\title{
Targeting the PI3K/AKT/MTOR pathway in KSHV-associated
}

\section{cancers}

\section{A Bhatt, P Bhende and B Damania*}

Address: Lineberger Cancer Center and Department of Microbiology \& Immunology, University of North Carolina-Chapel Hill, North Carolina, USA

* Corresponding author

from I I th International Conference on Malignancies in AIDS and Other Acquired Immunodeficiencies (ICMAOI): Basic, Epidemiologic, and Clinical Research

Bethesda, MD, USA. 6-7 October 2008

Published: 17 June 2009

Infectious Agents and Cancer 2009, 4(Suppl 2):O7 doi:10.1 186/I750-9378-4-S2-O7

This abstract is available from: http://www.infectagentscancer.com/content/4/S2/O7

(c) 2009 Bhatt et al; licensee BioMed Central Ltd.

Kaposi's sarcoma-associated herpesvirus (KSHV) is linked to three different human cancers: Kaposi's sarcoma (KS), primary effusion lymphoma (PEL) and multicentric Castleman's disease (MCD). We have previously reported that the PI3K/Akt/mTOR pathway is critical for the survival of KSHV-infected endothelial cells and B cells, and have demonstrated that Rapamycin/Sirolimus, an inhibitor of mTOR, can induce PEL cell death in vitro and in vivo (Sin et al., Blood. 2007. 109(5):2165-73). We have now extended these findings and demonstrate that therapeutic targeting of other members of the PI3K/Akt/mTOR signal transduction pathway can also induce cell death in PEL in vitro and inhibit tumor growth in murine xenograft models. Importantly, some of these novel drug candidates have passed clinical trials for other indications and can therefore be tested for efficacy against KS and AIDS-associated lymphomas. 